\title{
Analysis on the Impact of Financial Intelligence on Requirements for the Quality of Accounting Information
}

\section{Congcong Gou}

School of Finance and Economics Management, Sichuan University of Arts and Science, Dazhou, China

Email: 295028320@qq.com

How to cite this paper: Gou, C.C. (2020) Analysis on the Impact of Financial Intelligence on Requirements for the Quality of Accounting Information. Open Access Library Journal, 7: e6592.

https://doi.org/10.4236/oalib.1106592

Received: July 7, 2020

Accepted: July 21, 2020

Published: July 24, 2020

Copyright $\odot 2020$ by author(s) and Open Access Library Inc.

This work is licensed under the Creative Commons Attribution International License (CC BY 4.0).

http://creativecommons.org/licenses/by/4.0/

\begin{abstract}
With the rapid development of economy and the progress of science and technology, a series of emerging industries have developed. Among them, represented by "artificial intelligence (AI)", the intelligent era is coming. In the rapidly rising $\mathrm{AI}$ environment, in order to meet the needs of the changing times, intelligent machines such as financial robots are gradually introduced into the field of accounting to be engaged in some basic and auxiliary financial work instead of accountants. This is called "financial intelligence". Whether the emergence of financial intelligence has a significant impact on the development of accounting theory is worthy of academic research. This paper studies the breakthrough of the connotation definition of requirements for the quality of accounting information from the perspective of financial intelligence, focuses on the analysis of requirements for prudence and timeliness of the quality of accounting information, On the other hand, the paper analyzes the impact of financial intelligence environment on the quality of accounting information, finds out new requirements for improving the quality of accounting information, and further improves the accounting system, proposes more comprehensive requirements affecting the quality of accounting information, and provides reference for the learning of accounting theory.
\end{abstract}

\section{Subject Areas}

Accounting

\section{Keywords}

Financial Intelligence, Quality of Accounting Information, Reliability, Prudence, Timeliness 


\section{Introduction}

Since "AI" was included in the work report of the government in 2017, there has been an upsurge of "AI" in China. With the rapid development of AI, a series of intelligent machines represented by financial robots are gradually introduced into the field of accounting. Financial intelligence has brought many changes to the development of companies. The impact of financial intelligence on the quality of accounting information is especially outstanding. Before that, many scholars at home and abroad only made a lot of researches on financial intelligence and the quality of accounting information respectively, but few of them analyzed on the same platform [1]. Financial intelligence brings convenience to the financial work undeniably. It improves the efficiency of accounting work, ensures the quality of accounting information to a certain extent, and promotes the development of enterprises. However, at the same time, it puts forward new thinking on requirements for safety and reliability of accounting information. In order to make the financial intelligence better combine with requirements for the quality of accounting information, make the intelligence adapt to the actual accounting work, and allow requirements for the quality of accounting information to be adjusted with the arrival of financial intelligence, this paper selects the impact on the connotation of requirements for the quality of accounting information in the environment of financial intelligence to analyze the advantages and disadvantages brought by financial intelligence to the financial work, and study the aspects from which the connotation of requirements for the quality of accounting information can be improved, so as to expand the connotation of requirements for the quality of accounting information and enable financial managers and decision makers to change the information they select and focus on in the environment of intelligence.

\section{Connotation Analysis of Requirements for the Quality of Accounting Information in the Environment of Financial Intelligence}

\subsection{The Meaning and Application Background of Financial Intelligence}

Financial intelligence is a kind of business intelligence. It mainly refers to the use of AI technology and a lot of electronic financial data of enterprise to establish a computer model for the traditional financial analysis model, so as to get the analysis and diagnosis report of enterprise operation. On March $10^{\text {th }}, 2016$, Deloitte, one of the world's four largest accounting firms, cooperated with Kira Systems, and formally introduced AI into financial work. The financial management entered a new era. With the pace of Deloitte, other famous accounting firms in the world introduced AI and launched the financial robot solution. At the 2017 Global Forum of China Management in Shanghai, Kingdee launched a cloud-based financial robot. RPA (robot process automation) technology has been introduced by more than $10 \%$ of organizations in the world in 2016 . With 
the continuous improvement of intelligent technology, it is expected that RPA technology will be introduced in a higher proportion in the future [2].

\subsection{Definition of Connotation of Requirements for the Quality of Accounting Information}

Whether the accounting information reflects the actual situation of an enterprise comprehensively, systematically and correctly can be divided into eight aspects: reliability, relevance, comprehensibility, comparability, substance over form, importance, prudence and timeliness. This is the definition of requirements for the quality of accounting information in the basic standards of the new accounting standards. The content in the new accounting standards is only the definition of the current manual financial system and accounting information system. In the environment of financial intelligence, the definition of requirements for the quality of accounting information should be broader and more targeted, so as to better adapt to the development of financial intelligence. For example, the definition of reliability, prudence, timeliness and other requirements should be more comprehensive.

\subsection{Connotation Analysis of Specific Requirements for the Quality of Accounting Information in the Environment of Financial Intelligence}

\subsubsection{Connotation Analysis of the Requirement for "Prudence"}

"Prudence" is an indispensable principle in any financial work. In the traditional manual accounting system, it requires financial personnel to stay prudent in actual work and select the reasonable accounting treatment method according to certain professional judgment. In the "AI" environment, the nature and application of prudence have changed.

In the environment of financial intelligence, the requirement for "prudence" changes mainly in the aspects of assets and cost measurement. In terms of assets, under the traditional accounting method, a company's treatment of the development costs of intangible assets and the depreciation of fixed assets is based on requirements of the new accounting standards [3]. At the end of each year, the company invests a lot of manpower and financial resources in comprehensive inspection of various assets, and requires the financial personnel to reasonably predict the possible losses and make provision for impairment. The application of "prudence" in terms of assets by the company mainly depends on the professional judgment ability of accountants, but in the new "AI" environment the requirement for "prudence" in terms of assets is not used reasonably. RPA technology is in the primary stage, technology has limitations, and the financial robot cannot make on-the-spot inspection on some assets or use professional ability to make reasonable provision for impairment according to the actual situation. Therefore, the company's assets are inflated at the end of the year. In terms of cost measurement, the company's production scale is usually expanding day by day, and the borrowing costs are increasing day by day. Under the traditional 
accounting method, the company has always recognized the borrowing costs according to whether they meet the capitalization conditions. Those that meet the capitalization conditions are included in the cost of relevant assets, while those that do not meet the capitalization conditions are recognized as expenses and included in the current profit and loss. After the realization of financial intelligence, due to technical defects, "AI" program will treat all borrowing costs as meeting the capitalization conditions, which underestimates the current profit and loss of the company.

The rational use of "prudence" in the quality of accounting information largely depends on the professional judgment ability of enterprise personnel. However, RPA technology does not have the professional quality and cognitive ability of accounting personnel. It lacks the professional judgment ability, so it cannot treat the recognition of relevant income and the measurement of expenses of the company according to the actual situation. This is contrary to the concept that "it is better to predict possible losses than to predict possible benefits". It makes the company overestimate the income and underestimate the cost, makes the enterprise's profits inflated, brings a great threat to the reliability of the enterprise accounting information, and seriously damages the interests of the company.

\subsubsection{Connotation Analysis of the Requirement for "Timeliness"}

The disclosure of financial information has timeliness. The more timely the information is provided, the higher the utilization value of information is. The requirement for "timeliness" is one of the important principles of requirements for the quality of accounting information. Under the traditional accounting method, it will take a long time to treat the accounting information due to its quantity and complexity, which affects the timeliness of utilization, and it is characterized by obvious lag. In the environment of financial intelligence, the provision of accounting information has obvious advantages in time.

Before financial intelligence is realized, the company usually begins to collect and sort out all kinds of original documents after the completion of business, and then completes the accounting work. There is a certain lag in time and the efficiency is not high. After the introduction of RPA technology, the financial robot completes the work of collecting and sorting out documents and accounting based on them. The robot can complete the work that has to be completed manually for dozens of minutes in a few minutes. Moreover, the financial robot can work continuously for 24 hours a day to deal with a huge workload, which greatly ensures the timeliness of collection and sorting out of accounting information. The financial robot Not only has changed the accounting, but also is different from the manual operation when the annual financial report is issued. A company usually provides the annual financial report about 4 months after the end of each year. It takes a long time and the users of financial accounting reports cannot grasp the company's information in a timely manner. After the introduction of RPA technology by the company, the powerful data analysis sys- 
tem can enable the financial robot to provide detailed financial reports within a few days after the end of the year, which greatly reduces the time.

In the intelligent environment, the timeliness of accounting information has been guaranteed to the highest degree. The financial robot can timely carry out accounting and provide all kinds of accounting information, which ensures the timeliness of accounting information. At the same time, more financial staffs will devote more energy into the bond investment of the company, accounting treatment of special business such as debt restructuring and the improvement of their own professional ability, which can help to improve the overall work efficiency and accuracy of the financial department and the overall professional ability of the financial department. Second, the company can issue all kinds of reports and information in a short time, which has an important impact on the long-term development of the company. After the realization of financial intelligence, the timeliness of accounting information is significantly improved. Without information delay, the decision makers can adjust the decision-making plan in a timely manner and respond to the market environment better.

\subsubsection{Connotation Analysis of Other Requirements of the Quality of Accounting Information}

Relevance: Whether accounting information is useful depends largely on the relevance of accounting information. In the definition of International Accounting Standards Board (IASB) and America's Financial Accounting Standards Board (FASB), requirement for relevance of accounting information is clearly explained. For accounting information, whether it is closely related to the users of information, whether it can play a role in decision-making, or whether it can be provided to users in a timely manner before the information becomes invalid are the embodiment of requirement for relevance [4]. Employees who have many years of accounting experience in the company accurately analyze and judge the information needed by users and the information that can play a role in decision-making by professional judgment, so as to make accounting information reliable and effective. In the environment of financial intelligence, due to the limitations of intelligent technology, the robot can only report all the information involved in the financial accounting work according to the traditional financial reporting mode, and will not consider the value of the information to the users, which will lead to the decline of the quality of accounting information.

Comprehensibility: Whether accounting information can be understood by users of information is very important. Specifically, when providing accounting information, information providers should fully understand the personal preferences of information users, their attitude towards risk and the decision-making model they use, and fully consider the understanding ability and professional ability of users of accounting information. The accounting information provided to them must be simple and clear and can be accepted and understood by them. For any decision maker, whether accounting information can help them to make decisions, the ability to understand information is also indispensable [5]. Clear 
and easy-to-understand accounting information can undoubtedly save more energy and time, and give decision makers evidence. In the modern environment of financial intelligence, the financial robot can only provide the society with conventional and understandable accounting information, which tends to be popular. It cannot provide the corresponding information according to the personal preferences of each decision maker, their attitude towards risk and the decision-making model they use, so that the decision maker can make decisions quickly and accurately. This is a major defect of modern RPA technology.

\section{New Requirements for Improving the Connotation of the Quality of Accounting Information}

\subsection{Suggestions on Improving the Connotation of Requirement for "Prudence"}

The deep application of financial intelligence can improve the accuracy of data to the greatest extent. It can make full use of big data mining technology to analyze financial data, deeply analyze the probability of future events, and fully predict the probability of occurrence or nonoccurrence to improve the accuracy and precision of financial data confirmation and measurement. Seen from the future development trend of financial intelligence, the requirement for "prudence" under the traditional accounting method should be reduced, Greatly reduce the uncertainty of information reflected in financial statements, so that the financial information and data can be more accurate and reflect the events with a large probability.

\subsection{Suggestions on Improving the Connotation of Requirement for "Timeliness"}

In the environment of financial intelligence, all kinds of accounting becomes faster, the preparation time of financial accounting report is greatly reduced, enterprise decision makers and information users have more sufficient time to process and analyze the information. In this environment, an enterprise should pay special attention to making good use of time, make timely and efficient analysis and decision of various reports, put more energy into the work of the next accounting period, and make corresponding arrangements reasonably. At this time, the enterprise should change the focus of the requirement for timeliness of accounting information to more attention on whether the decision makers use the information in a timely manner and make timely decision-making arrangements.

\subsection{Suggestions on Improving the Connotation of Other Requirements for the Quality of Accounting Information}

The application of financial intelligence in the field of accounting can improve the speed of data processing, greatly improve the accuracy and precision of data processing, and complete many tasks that cannot be completed manually. How- 
ever, machines are machines and they are still at a very primary stage in terms of intelligence. There is still a big gap with human intelligence. A robot processes financial data according to the program set in advance, and cannot change by environment. It does not have human emotions, and cannot reach the accuracy and fineness of professional judgment ability of accountants. Therefore, in terms of the relevance and comprehensibility of requirements for the quality of accounting information, the traditional accounting mode should be used for processing. Therefore, in the era of financial intelligence in the field of accounting, we should give full play to the advantages of robots and human, expand the scope of data comparison for the relevance and comprehensibility in requirements for the quality of accounting information, give full play to intellectual and emotional advantages of accountants in the actual situation, and operate the man-machine dual system.

\section{Conclusion}

This paper interprets the connotation requirements of the quality of accounting information under the traditional accounting mode, and then expands the accounting model with the help of the in-depth application of financial intelligence in the field of accounting, and puts forward new requirements for the safety, timeliness, accuracy and reliability of financial information, which breaks through the connotation of the traditional requirements for the quality of accounting information. In order to improve the new requirements of financial intelligence on the quality of accounting information, this paper deeply analyzes the quality requirements such as "prudence", "timeliness", "relevance" and "comprehensibility", finds out the bottleneck for breakthrough of connotation, and gives innovative suggestions for reference. This paper does not study the influence factors of "importance", "substance over form", "reliability", "relevance" and other quality requirements in the financial intelligence environment, and has not put forward new requirements for the quality of accounting information.

\section{Conflicts of Interest}

The author declares no conflicts of interest regarding the publication of this paper.

\section{References}

[1] Zou, R.M. and Cheng, Z.H. (2018) The Era of Financial Accounting Intelligence Will Come. Metallurgical Accounting, 37, 19-21.

[2] Qiu, M. (2017) Kingdee "Black Technology" of Financial Intelligence, Launches the Financial Robot. Computer and Network, 43, 35.

[3] Wang, J. (2017) Analysis on the Impact of Big Data on Accounting and Coping Strategies. New Accounting, No. 12, 39-42.

[4] Lin, T. (2017) First Exploration on the Path of Improving the Reliability of Enterprise Accounting Information. China International Finance and Economics, No. 22, 
19-21.

[5] Feng, Y. and Gao, S.C. (2011) Analysis on Correlation and Reliability of Accounting Information in the New Economic Environment. Financial Supervision, No. 5, 26-27. 